\title{
The Research of Nanocrystallized Realgar for the Treatment of Skin Cancer
}

\author{
Yuanfu Qi, Xiurong Li, Huijie Li, Yi Zheng
}

The Department of Oncology of the Affiliated Hospital of Shandong University of TCM, Jinan City, China.

Email: qiyuanfu@163.com, lixr2000@126.com,2008lihuijie@163.com, zhengyizyyf@163.com

Received March $31^{\text {st }}, 2013$; revised May $1^{\text {st }}, 2013$; accepted May $10^{\text {th }}, 2013$

Copyright (C) 2013 Yuanfu Qi et al. This is an open access article distributed under the Creative Commons Attribution License, which permits unrestricted use, distribution, and reproduction in any medium, provided the original work is properly cited.

\begin{abstract}
Objective: To observe the effects and mechanisms of nanocrystallized realgar for the treatment of skin cancer. Methods: The clinical part was observing the therapeutic effect for the skin ulceration by externally using the nanocrystallized realgar. The experimental part was culturing the human squamous cell carcinoma A431 cells (A431) in vitro environment, estimating the effects of proliferation and apoptosis of A431 by MTT method and flow cytometry, and observing the effects on the expression of Survivin, Caspase-3 by RT-PCR method. Results: External treatment with nanocrystallized realgar had a therapeutic effect for the skin ulceration; it can promote the ulcers of skin cancer and skin metastasis healing. The experiments confirmed that nanocrystallized realgar can inhibit the A431 proliferation, induce the cells apoptosis, promote the expression of Caspase- 3 and reduce the expression of Survivin. And the experiments also found that the effects were in a concentration-dependent manner, and they have a synergistic effect with cis-Dichlorodiamineplatinum (DDP). Conclusions: External treatment with nanocrystallized realgar for the patients of skin cancer or skin metastasis achieved satisfactory therapeutic effects by inhibiting A431 proliferation and inducing these cells apoptosis. The mechanism might be associated with promoting the expression of Caspase-3 and reducing the expression of Survivin.
\end{abstract}

Keywords: Skin Cancer; Nanocrystallized Realgar; Ulceration; Inhibition of Proliferation; Induction of Apoptosis

\section{Introduction}

Skin cancer mainly contains two types: the basal cell carcinoma and the squamous cell carcinoma. The squamous cell carcinoma has a higher disease incidence, which accounts for almost $78.5 \%$ to $90.9 \%$ of all the skin cancer [1]. Currently, surgery is still the most effective one in all the treatments. However, to these patients who are not suitable for surgical treatment or need to prevent the recurrence after surgery, the study of effective anti-tumor drug seems particularly important. Realgar is one of the commonly used mineral Chinese medicines, and its main component is arsenic which has positive effects in antitumor. Meanwhile it also has many disadvantages, such as potentially toxic, insoluble, etc. However, the nanocrystallized realgar has a better bioavailability and pharmacodynamics, and shows little side effects [2]. Through the clinical observation and the experiment, we want to see whether the nanocrystallized realgar has therapeutic effect for the skin ulceration and try to explore the related mechanisms.

\section{Preparation of Nanocrystallized Realgar}

The realgar which was purchased from Shanxi Kanghui Pharmaceutical Co. Ltd. (production batch number 091201), was nanocrystallized by the lapping machine LVM-80WE of Shandong Longmai Technology Company, and then was detected by the photons nanometer laser particle size analyzer (model Winner 801) of the Jinan Winner Particle Instruments, Inc. for the size of the crystal particle. The average particle size was $72.79 \mathrm{~nm}$, which was in line with the requirements of nano-pharmaceutical.

\section{Clinical Observations}

\subsection{Selection of Cases}

The cases should be these patients with skin ulceration who had been diagnosed skin cancer or skin metastasis with clear pathological diagnosis, and without the interference of the radiotherapy, chemotherapy and the targeting drugs during the treatment. 


\subsection{Methods}

The skin ulcer was cleaned and disinfected, and then was coverd by a sheet of nanocrystallized realgar (the ulcer should be whole covered; the dose of nanocrystallized realgar should be according to the size of the wound); and then the ulcer was covered by the oil-gauze; finally, it was fixed with sterile gauze. This treatment was done once a day.

\subsection{Evaluation Criteria of Response}

- Complete remission: skin lesions subsided, only leaving hyperpigmentation or hypopigmentation;

- Remission: the original pathological changes were not found in the biopsy;

- Partial remission: skin lesions reduced $>50 \%$;

- No reaction: lesions reduced $<50 \%$ or no significant changes [3].

\subsection{Patients' General Information}

- Zhang, male, 69 years old, has an extrahepatic tumor on the right tempus, size within $2.5 \times 1.3 \mathrm{~cm}$, which postoperative pathological diagnosis is skin squamous cell carcinoma. The tumor recurred in 5 months after the operation with skin ulcer and exudates. The patient refused re-operation and wanted treatment of traditional Chinese medicine. Then the patient was giving treatment of external using the nanocrystallized realgar.

- Jiang, female, 65 years old, breast cancer with a skin metastasis ulcer on the right breast, the size of ulcer was about $5 \times 3 \mathrm{~cm}$. The patient refused operation and chemotherapy, and chose the treatment of traditional Chinese medicine by internal using decoction and external using the nanocrystallized realgar.

\section{The Experiments}

\subsection{The Main Materials}

Human skin squamous cell carcinoma A431 cells (purchased from Peking Union Medical College, China); the Thiazolyl Blue, the total RNA extraction kit (Beijing Solarbio biotech companies); Annexin V FITC KIT apoptosis detection kit (Beijing SizhengBai biological Company), DMEM high glucose medium (Thermo Fisher biochemical products company), fetal bovine serum (Hangzhou Evergreen biological Corporation), DDP (Qilu Pharmaceutical Factory); Casepase-3 (upstream: GTGGAATTGATGCGTGATG, downstream: GGAATC TGTTTCTTTGCATG, molecular weight of $500 \mathrm{bp}$ ) survivin (upstream: TTCTCAAGGACCACCGCATCT, downstream: CGCACTTTCTCCGCAGTT, molecular weight of $358 \mathrm{bp}$ ), $\beta$-actin (upstream: GACTACCTCAT
GAAGGTC, downstream: GATCCACATCTGCTGGAA, fragment length $500 \mathrm{bp}$ ) the on downstream primer material (The Bo Shang bio-tech company).

\subsection{Preparation of Nanocrystallized Realgar Suspension}

Using $\mathrm{KCl}$ saturated nitric acid solution dissolved the realgar nanoparticles, adjusting $\mathrm{pH}$ to 7.0 with $\mathrm{NaOH}$, constanting volume with PBS to the concentration of 2 $\mathrm{mg} \cdot \mathrm{mL}^{-1}$, filter-sterilized and stored at $4^{\circ} \mathrm{C}$. The nanopaticles of realgar in were shown in Figure 1.

\subsection{To Observe the Proliferation of A431 by MTT Method}

The cell suspension was made with the logarithmic growth phase of A431, adjusted the cells' density; and then the cells were inoculated into a 96-holes culturing plate for the further culture. When the cells were complete adherent, them were divided into different groups as the grouping principles(each group has 5 duplicate holes) and added drug: control group (concentration of $10 \%$ fetal bovine serum), group of concentration of $5 \%$ nanocrystallized realgar $\left(100 \mu \mathrm{g} \cdot \mathrm{mL}^{-1}\right)$, group of concentration of $10 \%$ nanocrystallized realgar $\left(200 \mathrm{ug} \cdot \mathrm{mL}^{-1}\right)$, group of concentration of $20 \%$ nanocrystallized realgar $\left(400 \mu \mathrm{g} \cdot \mathrm{mL}^{-1}\right)$, group of concentration of $25 \%$ (500 $\left.\mu \mathrm{g} \cdot \mathrm{mL}^{-1}\right)$, group of DDP $(2 \mu \mathrm{g} \cdot \mathrm{ml})$, combination group (DDP + group of concentration of 5\%,10\%, 20\%, 25\% nanocrystallized realgar). Cells in each duplicate hole would have been cultured for 24 hours; and at the 20th hour, every duplicate hole would be added 20 ul MTT (concentration was $5 \mathrm{~g} \cdot \mathrm{L}^{-1}$ ). After the last 4 hours, the supernatant of each duplicate hole were absorbed and discarded, then just added $200 \mu$ DMSO in each hole and shocked to make the crystals fully dissolve. Finally, the absorbance of each duplicate hole was tested by microplate reader within the wavelength of $490 \mathrm{~nm}$ and estimated the inhibitory arte of cell growth.

\subsection{To Estimate Cell Apoptosis by Flow Cytometry}

The cell suspension was prepared as above, adjusted the

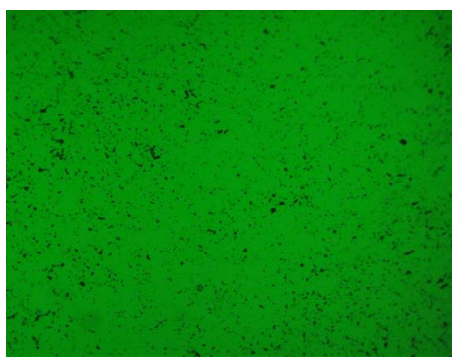

Figure 1. The nanopaticles of realgar $(\times 100)$. 
cell density, inoculated on average and continued to culture until the cells grew exuberantly and were adherent. Then they were divided as the grouping principles and added drug: control group (concentration of $10 \%$ fetal bovine serum), concentration of 5\% nanocrystallized realgar $\left(100 \mu \mathrm{g} \cdot \mathrm{mL}^{-1}\right)$, concentration of $10 \%$ nanocrystallized realgar group $\left(200 \mu \mathrm{g} \cdot \mathrm{mL}^{-1}\right)$, concentration of $20 \%$ nanocrystallized realgar group $\left(400 \mu \mathrm{g} \cdot \mathrm{mL}^{-1}\right)$, DDP group $\left(2 \mu \mathrm{g} \cdot \mathrm{mL}^{-1}\right)$ and combination group (DDP + concentration of $10 \%$ nanocrystallized realgar), which were continued to culture for 24 hours. And then the suspension was digested by $0.25 \%$ trypsin and centrifuged, while the supernatant was discarded. The cells were centrifuged twice with PBS. The single cell suspension was made as $1 \times$ into binding buffer and placed in streaming tube (each group contained six samples), added Annexin V-FITC and PI each $5 \mu \mathrm{L}$, fully mixed, and incubated in the dark at room temperature for 15 minutes; and then added $1 \times$ binding buffer, fully mixed; at last, estimated the cell apoptosis by flow cytometry.

\subsection{To Estimate the mRNA Expression of Survivin and Casepase-3 by RT-PCR Method}

The cells were processed as above, extracted total RNA of each group and detected the purity and the content of RNA by using ND-1000. The following steps were progressed according to the RT-PCR kit instructions, and then capturing pictures after electrophoresis by the Alpha gel imaging system, analyzing each of the target band and the internal reference gray value and estimating the relative expression.

\subsection{Statistical Methods}

Apple SPSS 17.0 software for statistical and analyze data with one-way ANOVA. Test $\mathrm{P}<0.05$ is considered statistically significant.

\section{Result}

\subsection{The Effect of External Treatment with Nanocrystallized Realgar}

- Zhang, after external treatment with nanocrystallized realgar 2 weeks, the exudate of skin ulceration disappeared; 2 month later, and the wounds began to shrink. The ulceration healed after 6 months. The skin lesions of the patient after the treatment were shown in Figure 2.

- Jiang, the ulceration healed after external treatment for 7 months. The swelling subsided, only left the pigmentation for the further treatment. The skin lesions of the patient before and after the treatment were shown in Figures 3-5.

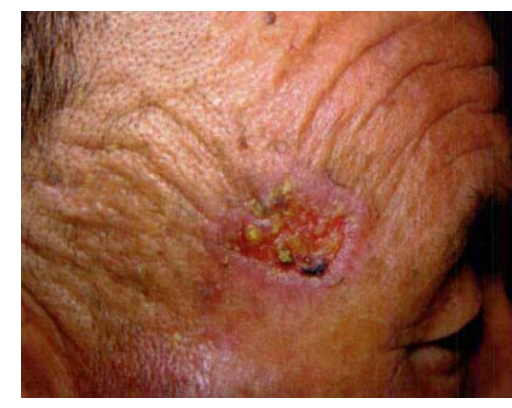

Figure 2. After treatment.

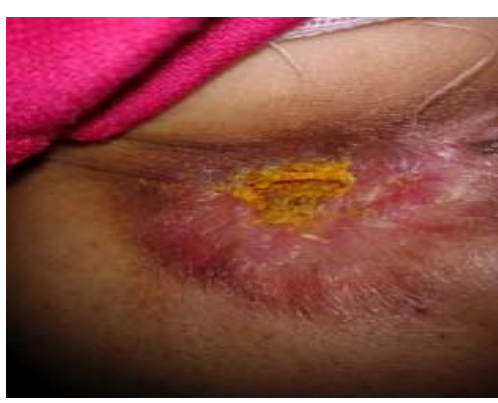

Figure 3. Treatment for 1 month.

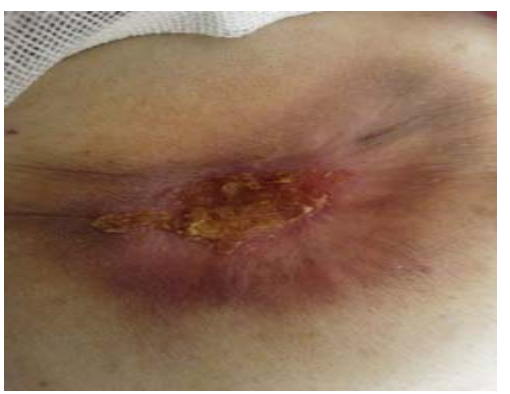

Figure 4. Treatment for 3 months.

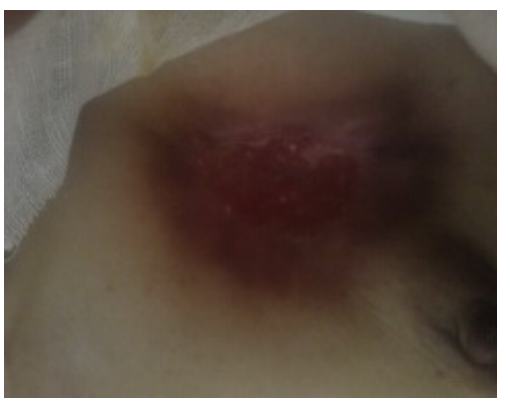

Figure 5. Treatment for 5 months.

\subsection{The Effect of Nanocrystallized Realgar on Cell Proliferation of A431 by MTT Method}

The results were shown in Table $\mathbf{1}$.

\subsection{The Effect of Nanocrystallized Realgar on Cell Apoptosis of A431 by Flow Cytometry}

The apoptosis rate is mainly reflected in the rate of early 
Table 1. The effect of nanocrystallized realgar on cell proliferation of A431 by MTT method.

\begin{tabular}{|c|c|c|}
\hline Groups & $A(n=6)$ & $\begin{array}{c}\text { The inhibition } \\
\text { rate/\% }\end{array}$ \\
\hline The control group & $0.966 \pm 0.079$ & - \\
\hline $5 \%$ nanocrystallized realgar & $0.930 \pm 0.081^{\star}$ & 3.80 \\
\hline $10 \%$ nanocrystallized realgar & $0.873 \pm 0.048^{\triangle \star}$ & 9.71 \\
\hline $20 \%$ nanocrystallized realgar & $0.823 \pm 0.051^{\triangle \star}$ & 14.83 \\
\hline $25 \%$ nanocrystallized realgar & $0.767 \pm 0.049^{\triangle \star}$ & 20.58 \\
\hline DDP group & $0.603 \pm 0.052^{\triangle}$ & 37.57 \\
\hline $\begin{array}{l}5 \% \text { nanocrystallized } \\
\text { realgar }+\mathrm{DDP}\end{array}$ & $0.564 \pm 0.034^{\triangle \boldsymbol{\Lambda}}$ & 41.68 \\
\hline $\begin{array}{l}10 \% \text { nanocrystallized } \\
\text { realgar + DDP }\end{array}$ & $0.526 \pm 0.044^{\triangle \star \star}$ & 45.58 \\
\hline $\begin{array}{l}20 \% \text { nanocrystallized } \\
\text { realgar + DDP }\end{array}$ & $0.486 \pm 0.047^{\triangle \Delta \star}$ & 49.75 \\
\hline $\begin{array}{l}25 \% \text { nanocrystallized } \\
\text { realgar + DDP }\end{array}$ & $0.446 \pm 0.050^{\triangle} \star \star$ & 53.84 \\
\hline
\end{tabular}

PS: compared with the control group ${ }^{\triangle} \mathrm{P}<0.05$; each combination group compared to monotherapy group with the same dose of nanocrystallized realgar ${ }^{\boldsymbol{\Lambda}} \mathrm{P}<0.05$; compared with the DDP group ${ }^{\star} \mathrm{P}<0.05$.

stage. the early apoptosis rate of each concentration nanocrystallized realgar group, DDP group, as well as the combination group were significantly higher than control group $(\mathrm{P}<0.05)$; and with the concentration of nanocrystallized realgar increasing, the early apoptosis rate significantly increased $(\mathrm{P}<0.05)$; the combination group's early apoptosis rate is significantly higher than that of each concentration nanocrystallized realgar group and DDP group $(\mathrm{P}<0.01)$. The results were shown in Table 2.

\subsection{The Effects of Nanocrystallized Realgar on the Expression of Survivin mRNA, Casepase-3 mRNA by RT-PCR Method}

The numeric of relative gray of Survivin of all group were significantly lower than the control group $(\mathrm{P}<$ $0.05)$; the numeric of relative gray of Casepase- 3 of all group were significantly higher than the control group ( $\mathrm{P}$ $<0.05)$. The expression of Survivin and Casepase-3 were in association with the concentration of the nanocrystallized realgar. Among these groups, there was a significant difference between each other $(\mathrm{P}<0.05)$. The numeric of relative gray of Survivin and Casepase- 3 of the DDP group were significantly different with each concentration of nanocrystallized realgar group; the numeric of relative gray of Survivin and Casepase-3 of the combination group were remarkabliy different with each concentration of nanocrystallized realgar group and DDP group $(\mathrm{P}<0.05)$. The results were shown in Table 3.
Table 2. The effect of nanocrystallized realgar on cell apoptosis of A431 by flow cytometry.

\begin{tabular}{ccc}
\hline Groups & $\mathrm{n}$ & The apoptosis rate/\% \\
\hline The control group & 6 & $0.76 \pm 0.14$ \\
$5 \%$ nanocrystallized realgar & 6 & $1.23 \pm 0.17^{\triangle \star}$ \\
$10 \%$ nanocrystallized realgar & 6 & $2.69 \pm 0.24^{\triangle \star}$ \\
20\% nanocrystallized realgar & 6 & $3.72 \pm 0.64^{\triangle \star}$ \\
DDP group & 6 & $5.33 \pm 0.57^{\triangle}$ \\
$10 \%$ nanocrystallized realgar + DDP & 6 & $7.45 \pm 0.61^{\triangle \star}$
\end{tabular}

PS: compared with the control group ${ }^{\triangle} \mathrm{P}<0.05$; compared with the DDP group ${ }^{\star} \mathrm{P}<0.05$.

Table 3. The effects of nanocrystallized realgar on the expression of Survivin mRNA, Casepase-3 mRNA by RTPCR method.

\begin{tabular}{cccc}
\hline Groups & $\mathrm{n}$ & Survivin/\% & Casepase-3/\% \\
\hline The control group & 6 & $68.74 \pm 1.96$ & $26.26 \pm 2.07$ \\
$5 \%$ nanocrystallized realgar & 6 & $63.93 \pm 3.57^{\triangle \star}$ & $32.66 \pm 4.42^{\triangle \star}$ \\
$10 \%$ nanocrystallized realgar & 6 & $57.12 \pm 3.93^{\triangle \star}$ & $35.29 \pm 5.26^{\triangle \star}$ \\
20\% nanocrystallized realgar & 6 & $47.64 \pm 6.44^{\triangle \star}$ & $38.52 \pm 8.37^{\triangle \star}$ \\
DDP group & 6 & $41.44 \pm 4.83^{\triangle}$ & $45.69 \pm 4.19^{\triangle}$ \\
$\begin{array}{c}\text { 10\% nanocrystallized } \\
\text { realgar+ DDP }\end{array}$ & 6 & $32.18 \pm 4.10^{\triangle \star}$ & $52.98 \pm 6.52^{\triangle \star}$ \\
\hline
\end{tabular}

PS: compared with the control group ${ }^{\triangle} \mathrm{P}<0.05$; compared with the DDP group ${ }^{\star} \mathrm{P}<0.05$.

\section{Discussions}

Realgar is one of the most important mineral drugs in traditional Chinese medicine. It is firstly recorded in "Shen Nong's Herbal Classic" and has been used in China more than 2000 years. It contains arsenic and has multiple compositions. According to the records in the Chinese Pharmacopoeia, arsenic disulfide $\left(\mathrm{As}_{2} \mathrm{~S}_{2}\right)$ is the effective component of the pharmacological effects, which is accounted for $90 \%$. The functions of realgar are detoxication, insecticide, clearing damp, eliminating phlegm and treating malaria. It can be used in carbuncle, malignant boil, snake bites, parasitic diseases, abdominal pain, epilepsy, malaria [4]. Realgar works well in the clinical treatment of skin cancer and skin metastasis with ulceration; however, specific mechanism of realgar's function is not yet clear. Tumor's development is not only related with proliferation and abnormal differentiation of tumor cells, but also closely related with blocked apoptosis of tumor cells. Therefore, inhibition of tumor cells proliferation and induction of tumor cells apoptosis may be the key to eliminating tumors [5]. Modern researches show that realgar can play anti-tumor effect through many 
ways such as inhibition of DNA synthesis, induction of tumor cells apoptosis and enhancing of cellular immune function. The nanocrystallized realgar has more significant advantages than common realgar in the inhibition of cell proliferation and induction of apoptosis [6].

Apoptosis is the orderly and autonomy death of cells by gene regulation. It involves a series of roles such as activation of gene, expression of gene and regulation of gene. Death receptor pathway and mitochondrial pathway are the main apoptosis pathways. Both of them can lead to activation of caspases-3; and the activation of endonuclease induces the chain breaking and final apoptosis $[7,8]$. Caspase is the key enzyme that can execute apoptosis; meanwhile, it is also the central effecter of apoptosis. Survivin is an inhibitor of apoptosis protein. It has been the strongest inhibitor of apoptosis by far. Survivin can block apoptosis by inhibiting the activity of Caspase-3 and Caspase-7. The expressions of the two play a very important role in the occurrence, development and apoptosis of human skin squamous cell carcinoma $[9,10]$.

This article used a combination of clinical observations and experimental studies to observe the effects of nanocrystallized realgar in external treatment for patients of skin cancer or skin metastasis with ulceration, and explored the effect and possible molecular mechanisms of it in inhibition of proliferation and induction of apoptosis of human skin squamous cell carcinoma A431 strain. The clinical observation found that external treatment of skin cancer and skin metastasis with the application of nanocrystallized realgar could promote the skin ulcer healing. The experimental study by MTT method showed that nanocrystallized realgar could significantly inhibit the proliferation of A431 cells, and it appeared in a concentration-dependent manner. The effects of each concentration of realgar groups on the inhibition of growth of A431 cells were not obvious compared with the DDP group and the combination groups. The experimental study by flow cytometer showed that each concentration of realgar groups, DDP and combination groups could all induce early apoptosis of A431 cells, and the early apoptotic rate of A431 cells was positively correlated with realgar concentration. The effects of combination groups on early apoptosis of A431 cells were better than single using realgar or DDP. Results of RT-PCR analysis showed that nanocrystallized realgar, DDP and the combination could all significantly inhibit the expression of Survivin and promote the expression of Casepase-3; the expression of survivin was negatively correlated with the concentration of nanocrystallized realgar while the expression of Casepase- 3 was positively related. The effects of the combination groups were significantly better than single using realgar or the DDP. The combination of nanocrystallized realgar and DDP had a synergistic effect. The experiments preliminarily confirmed that the nano- crystallized realgar worked anti-tumor effects by inhibiting cell proliferation and inducing apoptosis; and the mechanisms might be related with up-regulation of Caspase3 expression and downregulation of Survivin expression.

In addition, a study of the effect and related mechanism of nanocrystallized realgar inhibiting skin squamous cell carcinoma A431 cells neovascularization is in progress. The research is still in early stage. And there are many shortcomings, for example, there is not a large sample of clinical observation and the experimental methods and indicators should be further refined and improved. We will explore in depth in the future work.

\section{REFERENCES}

[1] B. Zhao, "Clinical Dermatology," 3rd Edition, Jiangsu Science and Technology Publishing House, Nanjing, 2001, p. 1106.

[2] X. R. Li, H. J. Li and Y. Y. Lin, "Experimental Research of Mechanism of Nanocrystallized Realgar Inhibiting Skin Squamous Cell Carcinoma A431 Cells Neovascularization," Journal of Modern Oncology, Vol. 21, No. 2, 2013, pp. 232-234.

[3] T. J. Dougherty, "Photo Sensitizers: Therapy and Detection of Malignant Tumors," Photochemistry and Photobiology, Vol. 45, No. 6, 1987, pp. 879-889.

[4] National Pharmacopoeia Committee, "Chinese Pharmacopoeia (Part I)," Chinese Medical Science and Technology Press, Beijing, 2010, p. 316.

[5] M. L. Chen, S. Tan, G. Y. Zhang, et al., "The Effects of Triptolide on the Cell Proliferation and Apoptosis of the Cutaneous Squamous Cell Carcinoma A431," Journal of Central South University, Vol. 34, No. 7, 2009, pp. 638641.

[6] X. C. Ye, X. L. Yang and B. H. Xu, "The Research Progress of the Nanocrystallized Realgar," Journal of Progress in Chemistry, Vol. 21, No. 5, 2009, pp. 934-939.

[7] T. S. Gao, X. Q. Han and H. X. Yin, "The Effects of Bu Zhong Yi Qi Decoction on Apoptosis of Myocardial Cells and the Expression of the Protein of fas, fasL and Caspase-3 of the Rats with Hypothyroidism," Chinese Journal of Experimental Traditional Medical Formulae, Vol. 18, No. 10, 2012, pp. 236-240.

[8] X. Chen, J. Wang, X. S. Jiang, et al., "The Effects of Curcumol on the Expression of the Apoptosis-Inducing Factor of Lung Cancer A549 Cells, Poly ADP Ribose Polymerase and Caspase-3," Chinese Journal of Experimental Traditional Medical Formulae, Vol. 17, No. 19, 2011, pp. 157-159.

[9] M. M. Kavurma and L. M. Khachigian, "Signaling and Transcriptional Control of Fas Ligand Gene Expression," Cell Death Differ, Vol. 10, No. 3, 2003, pp. 36-44. doi:10.1038/sj.cdd.4401179

[10] A. Chakravarti, E. Noll, P. M. Black, et al., "Quantitatively Determined Survivin Expression Levels Are of Prognostic Value in Human Gliomas," Clinical Oncology, Vol. 20, No. 7, 2002, pp. 1063-1068. 